\title{
THE EFFECTS OF DEXAMETHASONE AND POTASSIUM CHLORIDE AS ADDITIVES TO LOCAL ANAESTHETIC IN SUPRACLAVICULAR BRACHIAL PLEXUS BLOCK: A RANDOMISED CONTROLLED STUDY
}

\author{
Ushakumary Reghunathan'1, Bindu Mele Veetil2, Radha Korumbil Raghavan³, Ausaf Ashik Karikannan Thodi ${ }^{4}$
}

${ }_{1}^{1}$ Additional Professor, Department of Anaesthesiology, Government Medical College, Kozhikode. ${ }^{2}$ Associate Professor, Department of Anaesthesiology, Government Medical College, Kozhikode. ${ }_{3}^{3}$ Additional Professor, Department of Anaesthesiology, Government Medical College, Kozhikode. ${ }^{4}$ Senior Resident, Department of Anaesthesiology, Government Medical College, Kozhikode.

\begin{tabular}{l}
\hline ABSTRACT \\
BACKGROUND AND AIMS \\
Supraclavicular brachial plexus block is ideal for upper limb surgical procedures. Dexamethasone and potassium chloride have \\
been used as adjuncts to prolong analgesia. We aimed to compare the effects of addition of dexamethasone or potassium chloride to \\
local anaesthetic solution of bupivacaine and lignocaine on the onset time of sensory and motor blockade and duration of blockade \\
in supraclavicular brachial plexus block in patients undergoing upper extremity surgeries.
\end{tabular}

\section{MATERIALS AND METHODS}

A prospective, randomized, double-blind control study was conducted on 90 healthy patients of ASA grade I/II of age group 2070 years scheduled for orthopaedic surgery of upper limb under supraclavicular brachial plexus block. Patients were allocated in to three groups of 30 each as Group L (Lignocaine+Bupivacaine), LD (Lignocaine+Bupivacaine+Dexamethasone), and LP (Lignocaine+Bupivacaine+Potassium chloride). The parameters observed were time of onset of sensory and motor block, total duration of analgesia, and side effects.

\section{RESULTS}

The mean duration of analgesia was longer in group LD (681.0 \pm 207.08 minutes) and LP (643.0 \pm 167.04 minutes) compared to group L (332.0 \pm 40.80 minutes) and was statistically significant $(\mathrm{P}<0.01)$ though the difference between group LD and LP was not significant $(\mathrm{P}=0.85)$. The mean time for onset of sensory block was $10.50 \pm 2.75$ minutes in group $\mathrm{L}, 9.80 \pm 2.12$ minutes in group LP, and 7.0 \pm 1.85 minutes in group LD. The onset of sensory block was earliest in group LD and this was statistically significant when compared to group $\mathrm{L}(\mathrm{P}<0.01)$ and group $\mathrm{LP}(\mathrm{P}<0.01)$ while the difference between groups $\mathrm{LP}$ and $\mathrm{L}$ was not significant $(\mathrm{P}=0.71)$. Mean time of onset of motor blockade in group L, group LP, group LD were $12.57 \pm 2.95$ min, $11.73 \pm 2.39$ minutes, and $8.63 \pm 1.79$ minutes respectively. Onset of motor block was earliest in group LD and this was statistically significant when compared to group L $(\mathrm{P}<0.01)$ and group LP $(\mathrm{P}<0.01)$ while the difference between groups $\mathrm{LP}$ and $\mathrm{L}$ was not significant $(\mathrm{P}=0.561)$.

\section{CONCLUSION}

Addition of potassium chloride $0.1 \mathrm{~mL}$ or dexamethasone $8 \mathrm{mg}$ to local anaesthetics for supraclavicular block, prolonged duration of analgesia without producing any major side effects. Dexamethasone is a better adjuvant than potassium chloride because it results in more rapid onset of sensory and motor blockade.

\section{KEYWORDS}

Lignocaine, Bupivacaine, Dexamethasone, Potassium Chloride, Analgesia, Supraclavicular Brachial Plexus Block.

HOW TO CITE THIS ARTICLE: Reghunathan U, Veetil BM, Raghavan RK, et al. The effects of dexamethasone and potassium chloride as additives to local anaesthetic in supraclavicular brachial plexus block: a randomised controlled study. J. Evolution Med. Dent. Sci. 2016;5(53):3522-3525, DOI: 10.14260/jemds/2016/812

\section{INTRODUCTION}

Pain is an unpleasant sensory and emotional experience associated with actual or potential tissue damage or described in terms of such damage. ${ }^{1}$ Regional anaesthesia of the trunk and the extremities is an alternative to general anaesthesia in many situations. ${ }^{2}$ It avoids the unwanted effects of the anaesthetic drugs used during general anaesthesia and the

Financial or Other, Competing Interest: None.

Submission 18-05-2016, Peer Review 13-06-2016,

Acceptance 17-06-2016, Published 02-07-2016.

Corresponding Author:

Dr. Ushakumary Reghunathan,

Harmony, D. P. O. Road,

Malappuram-676505.

Kerala, India.

E-mail: surgeonuk@gmail.com

DOI: $10.14260 /$ jemds $/ 2016 / 812$ stress of laryngoscopy and tracheal intubation. ${ }^{3}$ It was William Halsted ${ }^{4}$ who performed the first brachial plexus block using a surgical approach in the neck and he applied cocaine to the brachial plexus. The first percutaneous supraclavicular block was performed in 1911 by the German surgeon, Diedrich Kulen Kampff. ${ }^{5}$ It was Paul Ansbro who described continuous brachial plexus block technique. ${ }^{6}$ The subclavian perivascular block was first described by Winnie and Collins in $1964 .{ }^{7}$ Selander ${ }^{8}$ described a technique for continuous brachial plexus block using intravenous catheter secured in the axilla.

Supraclavicular approach to brachial plexus block is routinely used all over the world for surgeries of upper limb because of the anatomical ease of blocking nerve roots at this level. Typical features of this block include rapid onset and dense analgesia along with high success rate. 
Nowadays, different drugs have been used as adjuvants with local anaesthetics in supraclavicular blocks to prolong intraoperative anaesthesia and postoperative analgesia. The commonly used adjuvants are clonidine, opioids like buprenorphine and fentanyl, epinephrine, potassium chloride, sodium bicarbonate, dexamethasone, and magnesium chloride. Of these additives, potassium chloride, dexamethasone, and clonidine have been shown to have minimal side effects ${ }^{9}$. Many studies done previously have proved the advantages of using dexamethasone and potassium chloride as additives to local anaesthetics in supraclavicular block, but no study has been done to compare these two additives. This study was done to compare the effects of these two additives in supraclavicular block.

Movements of ions through the nerve membrane is considered one of the main steps in the process of excitation and propagation of nerve stimuli. A nerve impulse can be effectively blocked by accumulation of potassium ions outside the neuron. ${ }^{10}$ Thus, administration of exogenous potassium chloride will reinforce and prolong the blockade produced by bupivacaine. Dexamethasone, a steroid with antiinflammatory properties block the nociceptive impulse transmission along the unmyelinated $\mathrm{C}$ fibres ${ }^{11}$ and suppressing ectopic neuronal discharge. It might bring about this effect by altering the function of potassium channels in the excitable cells.

\section{MATERIALS AND METHODS}

After approval from the Hospital Ethics Committee, a prospective double blind randomized controlled study was conducted on 90 patients of ASA grade I/II in the age group of 20-70 years posted for various upper limb surgery.

Patients with allergic reactions to local anaesthetics, peripheral neuropathy, coagulation disorders, local infection at the site of injection, and history of seizures were excluded from the study.

After preoperative evaluation, the patient was briefed about the supraclavicular block to be performed, its advantages over general anaesthesia (GA) and also about the associated complications. Informed consent was obtained from every patient prior to the study and they were familiarized with the use of Visual Analogue Scale (VAS) scoring system.

Patients were randomised into three groups. Randomisation was done by allocating random number generated by the computer to each patient with each group consisting of 30 patients. All groups received a total of $30 \mathrm{~mL}$ of the local anaesthetic solution.

Group L (Control group) received $10 \mathrm{~mL}$ 1.5\% lignocaine with $1: 200,000$ adrenaline $+18 \mathrm{~mL} 0.25 \%$ bupivacaine $+2 \mathrm{~mL}$ sterile water.

Group LD (Dexamethasone group) received $10 \mathrm{~mL} \mathrm{1.5 \%}$ lignocaine with $1: 200,000$ adrenaline $+18 \mathrm{~mL} \quad 0.25 \%$ bupivacaine $+8 \mathrm{mg}$ dexamethasone.

Group LP (Potassium chloride group) received $10 \mathrm{~mL} \mathrm{1.5 \%}$ lignocaine with $1: 200,000$ adrenaline+18 $\mathrm{mL} \quad 0.25 \%$ bupivacaine $+0.2 \mathrm{mmol}$ potassium chloride $(0.1 \mathrm{ml})+1.9 \mathrm{~mL}$ sterile water.

The investigator, attending anaesthesiologist, and patients were unaware of the nature of group and drug allocation. Monitors were attached and baseline pulse, blood pressure (BP), respiratory rate, peripheral oxygen saturation $\left(\mathrm{SpO}_{2}\right)$ were recorded. Patient was positioned in supine and arm to be blocked was adducted and kept by the side. Intravenous access was secured with 18G Teflon cannula and IV Ringer's Lactate was started. All patients were premedicated with Inj. Midazolam 1mg and ondansetron $4 \mathrm{mg}$ IV. Head was turned to opposite side, shoulder was raised by a roll placed between the scapulae. The supraclavicular area was aseptically prepared and draped.

After a skin wheel with local anaesthetic approximately 1 $\mathrm{cm}$ above the mid clavicular point, $22 \mathrm{G} 5 \mathrm{~cm}$ insulated Stimuplex needle was introduced through the skin and directed just above and posterior to the subclavian pulse and advanced slowly in caudal, medial, and posterior direction. The needle was advanced until flexion of fingers were noted. If contraction was still observed when the nerve stimulator voltage decreased to $0.5 \mathrm{~mA}$, the local anaesthetic solution was injected after confirming negative aspiration of blood. Oxygen was administered at a rate of 3-5 L/min with face mask.

Vital parameters (Pulse, respiration, BP) were monitored every two minutes for 30 minutes and then every 10 minutes till the procedure was over and then every 1 hour till patient complained of pain equivalent to VAS score of 4 . The time of onset of sensory and motor block and total duration of analgesia were noted.

\section{Time of Onset of Sensory Block}

It is the time between the injection and complete abolition of pinprick sensation. Pinprick test was done with sterile 25G needle over the dermatomes $\mathrm{C} 4$ to $\mathrm{T} 2$ every minute till complete loss of pain sensation.

\section{Time of Onset of Motor Block}

It is the time between the injection and complete absence of voluntary movement of the limb.

\section{Duration of Analgesia}

Time between onset of analgesia and reappearance of pain or request for pain relief, corresponding to VAS score of 4 .

Postoperative analgesia was assessed by visual analogue scale half hourly. Rescue analgesia of Inj. Tramadol $50 \mathrm{mg}$ IM was given as per the requirement. At the end of the study decoding of data was done in all patients belonging to groups L, LD, and LP.

\section{Statistical Analysis}

The onset of sensory block, motor block, and duration of analgesia were compared using analysis of variance. Statistical analysis was performed by using ANOVA using the Computer Software Statistical Package for Social Sciences (SPSS). P $<0.05$ was considered as statistically significant.

\section{RESULTS}

All the 3 groups were similar with regards to age and weight (Table 1).

\begin{tabular}{|c|c|c|c|c|}
\hline Parameter & $\begin{array}{c}\text { Group L } \\
\text { (Mean+SD) }\end{array}$ & $\begin{array}{c}\text { Group LD } \\
\text { (Mean+SD) }\end{array}$ & $\begin{array}{c}\text { Group LP } \\
\text { (Mean+SD) }\end{array}$ & P \\
\hline Age (years) & $34.20 \pm 10.40$ & $35.83 \pm 9.24$ & $34.98 \pm 8.51$ & 0.798 \\
\hline Weight (Kg) & $51.13 \pm 8.25$ & $57.40 \pm 5.29$ & $58.63 \pm 5.58$ & 0.638 \\
\hline \multicolumn{5}{|c|}{ Table 1: Comparison of Demographic Parameters } \\
\hline
\end{tabular}

SD-Standard Deviation 


\section{Onset of Sensory Block}

The mean time of onset of sensory block was $10.50 \pm 2.75$ minutes in group L, $9.80 \pm 2.12$ minutes in group LP, and $7.0 \pm 1.85$ minutes in group LD (Fig. 1). The onset of sensory block was the earliest in group LD and this was statistically significant when compared to group $\mathrm{L}(\mathrm{P}<0.01)$ and group LP $(\mathrm{P}<0.01)$. Even though there was a difference in the time of onset of sensory block between group $L$ and LP, this difference was found to be statistically insignificant $(\mathrm{P}=0.71)$. [Table 2]

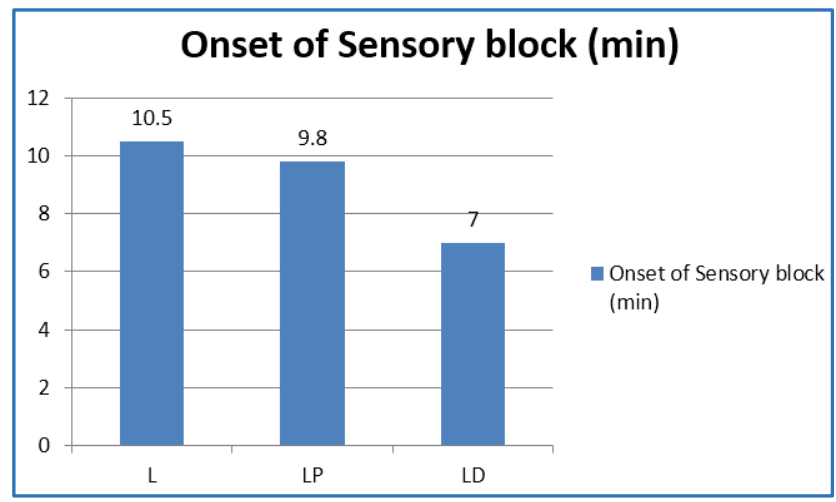

Fig. 1

\section{Onset of Motor Block}

The mean time for onset of motor block in group L, LP, and LD were $12.57 \pm 2.95$ minutes, $11.73 \pm 2.39$ minutes and $8.63 \pm 1.79$ minutes respectively (Fig. 2). The onset of motor block was earliest in group LD and this was statistically significant when compared to group L $(\mathrm{P}<0.01)$ and group LP $(\mathrm{P}=0.01)$. The difference of onset of motor block was found to be statistically insignificant between group LP and $\mathrm{L}(\mathrm{P}=0.561)$. [Table 2]

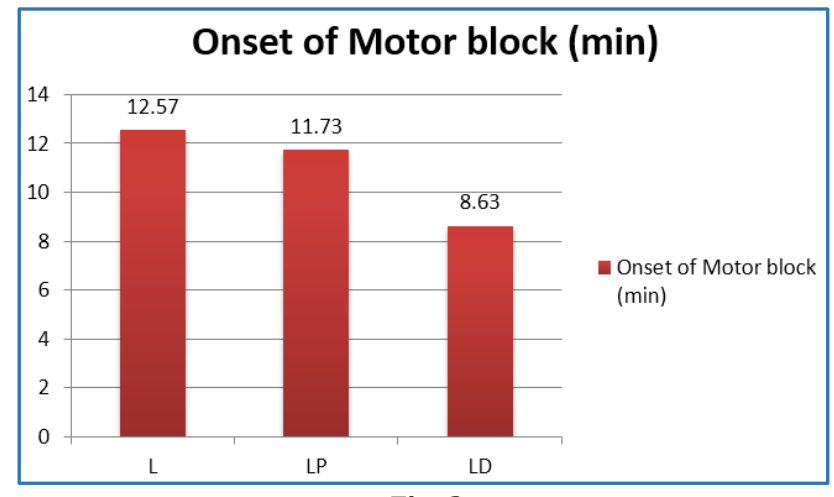

Fig. 2

\section{Duration of Analgesia}

Duration of analgesia was found to be highest in group LD with mean duration of analgesia ( $681.0 \pm 207.08$ minutes) followed by group LP, which was $643.0 \pm 167.04$ minutes and the least was in group L (332.0 \pm 40.80 minutes). [Fig. 3]

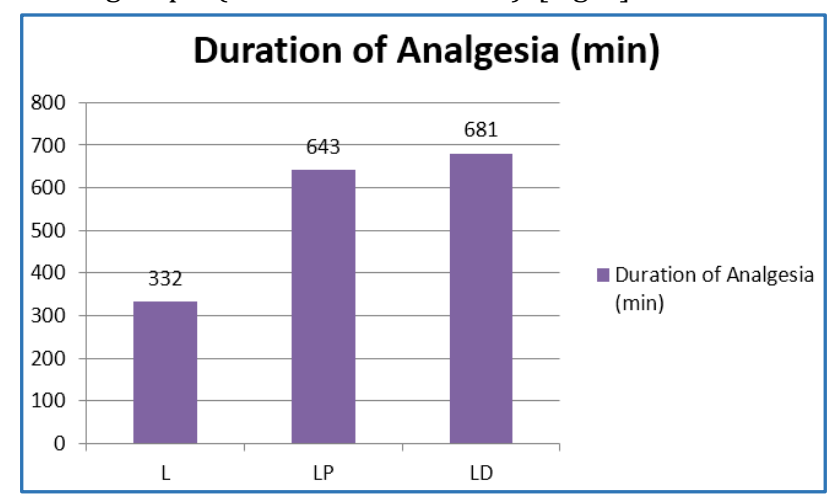

Fig. 3
The mean duration of analgesia in Group LD and LP were statistically significant when compared to Group L $(\mathrm{P}<0.01)$ while the difference between Groups LP and LD was statistically not significant $(\mathrm{P}=0.850)$. [Table 2]

\begin{tabular}{|c|c|c|c|c|c|c|}
\hline Variable & $\begin{array}{c}\text { Group L } \\
\text { (Mean } \\
\text { +SD) }\end{array}$ & $\begin{array}{c}\text { Group } \\
\text { LD } \\
\text { (Mean+ } \\
\text { SD) }\end{array}$ & $\begin{array}{c}\text { Group } \\
\text { LP } \\
\text { (Mean + } \\
\text { SD) }\end{array}$ & $\begin{array}{c}\text { P } \\
\text { Value } \\
\text { (LD } \\
\text { to L) }\end{array}$ & $\begin{array}{c}\text { P } \\
\text { Value } \\
\text { (LP } \\
\text { to L) }\end{array}$ & $\begin{array}{c}\text { P } \\
\text { Value } \\
\text { (LD } \\
\text { to LP) }\end{array}$ \\
\hline $\begin{array}{c}\text { Onset of } \\
\text { Sensory } \\
\text { Block (Min) }\end{array}$ & $\begin{array}{c}10.50 \pm \\
2.75\end{array}$ & $\begin{array}{c}7.0 \pm \\
1.85\end{array}$ & $\begin{array}{c}9.80 \pm \\
2.12\end{array}$ & $<0.01$ & 0.71 & $<0.01$ \\
\hline $\begin{array}{c}\text { Onset of } \\
\text { Motor } \\
\text { Block (Min) }\end{array}$ & $\begin{array}{c}12.57 \pm \\
2.95\end{array}$ & $\begin{array}{c}8.63 \pm \\
1.79\end{array}$ & $\begin{array}{c}11.73 \pm \\
2.39\end{array}$ & $<0.01$ & 0.561 & $<0.01$ \\
\hline $\begin{array}{c}\text { Duration of } \\
\text { Analgesia } \\
\text { (Min) }\end{array}$ & $\begin{array}{c}332.0 \pm \\
40.80\end{array}$ & $\begin{array}{c}681.0 \pm \\
207.08\end{array}$ & $643.0 \pm$ \\
167.04 & $<0.01$ & $<0.01$ & 0.850 \\
\hline \multicolumn{7}{|c|}{ Table 2: Comparison of Blockade } \\
\hline
\end{tabular}

The vitals were stable throughout the surgery in all the three groups. There were no major side effects in any of the groups. One patient in group L had emesis in the postoperative period, two patients in group LP, and one patient in group LD complained of nausea during surgery. Symptoms of all the patients were relieved on giving Inj. ondansetron $4 \mathrm{mg}$ intravenously.

\section{DISCUSSION}

Brachial plexus block is widely used in our practice for forearm and hand surgeries. It provides good intraoperative and postoperative analgesia. Our study demonstrated statistically significant faster onset of sensory and motor blockade and longer duration of analgesia in subjects receiving dexamethasone as adjuvant to local anaesthetic solution. ${ }^{12,13}$ Prolonged analgesia is of utmost importance in orthopaedic surgeries.

Dexamethasone has been studied as one adjuvant to local anaesthetic in peripheral nerve block. Because of easy availability, cost effectiveness, lack of significant side effects, dexamethasone has been selected as an adjuvant to local anaesthetic solution in brachial plexus block. Many studies evaluated effects of dexamethasone when added to local anaesthetic for brachial plexus block and concluded that it prolongs postoperative analgesia.

Steroids have nerve block prolonging effects. They produce analgesia by blocking transmission through nociceptive unmyelinated C-fibres and suppressing ectopic neuronal discharge. ${ }^{14}$ Dexamethasone-induced prolongation of peripheral nerve blockade is commonly attributed to its anti-inflammatory action. It also improves the quality and duration of analgesia over local anaesthetics alone. This is thought to be mediated by attenuating the release of inflammatory mediators reducing ectopic neuronal discharge and inhibiting potassium channel-mediated discharge of nociceptive C-fibres. Action on glucocorticoid receptor is proposed to alter the functioning of ion channels or produce local acidosis in nerve cell thereby reducing the concentration of local anaesthetic required to produce conduction failure or trapping the highly ionized bupivacaine molecule into the neuronal cell. Both these events would produce an extended 
action of local anaesthetics. The duration of analgesia was twice with addition of dexamethasone to local anaesthetics.

In our study, it was found that by adding dexamethasone to the local anaesthetics, the onset of sensory and motor blockade was significantly shortened compared to adding potassium chloride. Shrestha BR, Maharajan SK, Tabedar S also found significant difference in onset of sensory and motor blockade in local anaesthetics and steroid group. ${ }^{15}$

By adding potassium chloride, the duration of analgesia can be significantly increased when compared to local anaesthetic alone group as addition of potassium ions outside a nerve cell causes reduction of the resting membrane potential and causes conduction blockade. Similar results were observed by Kosha, et al. ${ }^{16}$ Kircha, et al ${ }^{17}$ reported that addition of potassium chloride doubled the duration of blockade produced by local anaesthetics.

Many studies done previously had proved the advantages of using dexamethasone or potassium chloride as additives to local anaesthetics in supraclavicular block. But, no study has been done to compare these two. In this study, we found that by adding dexamethasone, the sensory and motor blockade were more rapid compared to adding potassium chloride to the local anaesthetics. As far as duration of analgesia was concerned, both dexamethasone and potassium chloride increased the duration, but the difference between the two were not statistically significant.

\section{CONCLUSION}

It is concluded from this study that both potassium chloride and dexamethasone prolong the duration of analgesia when used with local anaesthetic solution containing lignocaine and bupivacaine for supraclavicular brachial plexus block without producing any major side effects. Dexamethasone is a better adjuvant than potassium chloride because, in addition to prolonging the duration of analgesia, it also results in more rapid onset of sensory and motor blockade.

\section{REFERENCES}

1. Abram SE. Chronic pain management. In: Barash PG, Cullen BF, Stoelting RK. Clinical anaesthesia, $5^{\text {th }}$ ed. Lippincott Williams and Wilkins, Philadelphia 2006:1449.

2. Michael FM. Peripheral nerve blockade. In: Barash PG, Cullen BF, Stoelting RK. Clinical anaesthesia, $5^{\text {th }}$ ed. Lippincott Williams and Wilkins, Philadelphia 2006:718.

3. Henderson J. Airway management in the adult. Miller's Anaesthesia, $7^{\text {th }}$ ed. Elsevier Churchill Livingstone 2009:1599-600.
4. Halsted WS. Practical comments on the use and abuse of cocaine; suggested by its invariably successful employment in more than a thousand minor surgical operations. N Y Med J 1885;42:294-5.

5. Kulenkampff D. Brachial plexus anaesthesia: its indications, technique and dangers. Annals of Surgery 1928;87(6):883-91.

6. Ansbro FP. A method of continuous brachial plexus block. American Journal of Surgery 1946;71:716-22.

7. Winnie AP, Collins VJ. The subclavian perivascular technique of brachial plexus anaesthesia. Anaesthesiology 1964;25:353-63.

8. Selander D. Catheter technique in axillary plexus block: presentation of a new method. Acta Anaesthesiologica Scandinavica 1977;21:324-9.

9. Sing S, Agarwal A. A study of the efficacy of clonidine added to bupivacaine as compared with bupivacaine alone in supraclavicular brachial plexus block for upper limb surgery. Indian Journal Anaesthesia 2010;54(6):552-7.

10. Aldrete JA, Barnes DR, Sidon MA, et al. Studies on effects of potassium chloride to lidocaine. Anaesthesia and Analgesia 1969;48(2):269-76.

11. Shresta BR, Maharjan SK, Shrestha S, et al. Comparative study between tramadol and dexamethasone as an admixture to bupivacaine in supraclavicular brachial plexus block. J Nepal Med Assoc 2007;46(168):158-64.

12. Urmey W. Upper extremity blocks: regional anaesthesia and analgesia. Philadelphia, WB Saunders Company 1996:254-78.

13. Movafeg A, Razazian M, Mohamadi FH, et al. Dexamethasone added to lidocaine prolongs axillary brachial plexus blockade. Anaesth Analg 2006;102(1):263-7.

14. Johansson A, Hao J, Sjolund B. Local corticosteroid application blocks transmission in normal nociceptive Cfibres. Acta Anaesthesiol Scand 1990;34(5):335-8.

15. Shrestha BR, Maharajan SK, Tabedar S. Supraclavicular brachial plexus block with and without dexamethasone- a comparative study. Kathmandu University Medical Journal 2003;1(3):158-60.

16. Khosa DS, Thind SS, Gupta HK, et al. Effects of adding potassium chloride to lignocaine and bupivacaine solution of the onset time and duration of brachial plexus block. Indian Journal of Anaesthesia 1990;38(8):119-22.

17. Kircha S, Barsa J, Fink BR. Potentiation of nerve block in vivo by physiological adjuvants in the solution. British Journal of Anaesthesia 1983;55(6):549-53. 